\title{
Evaluation of prescribing indicators and pattern among dermatological outpatients in a teaching hospital of central Nepal
}

\author{
Manohar Pradhan ${ }^{1}$, Mahesh Mathur ${ }^{2}$ \\ ${ }^{1}$ Dept. of Emergency Medicine, College of Medical Sciences, Bharatpur, Nepal \\ ${ }^{2}$ Dept of Dermatology, College of Medical Sciences, Bharatpur, Nepal
}

\section{Correspondence \\ Dr. Manohar Pradhan, \\ Dept. of Emergency Medicine, \\ College of Medical Sciences, \\ Bharatpur, Nepal \\ Email:drmpcms@gmail.com}

DOI: http://dx.doi.org/10.3126/ jemsn.v12i2.15452

Article received: April $1^{\text {st }} 2016$

Article accepted: May $30^{\text {th }} 2016$

\begin{abstract}
Background \& Objectives: Evaluation of prescribing indicators by proper analysis of prescriptions under the guidelines of World Health Organization enables us to detect some of the common problems of prescribing. Materials \& Methods: This study was conducted on randomly selected 325 prescriptions of dermatological outpatients of teaching hospital of College of Medical Sciences Bharatpur (Nepal) with an objective to detect the problems of prescribing as well as to delineate the pattern of medicines prescribing. Results: Total number of medicines prescribed on these prescriptions was 743. The average number of medicines per encounter was 2.28. Antihistamines, antifungals, corticosteroids and antibiotics were four most frequently prescribed therapeutic classes. One systemic as well as one topical medicine belonging to same therapeutic class was prescribed on about one-third of totally analyzed prescriptions. Cetrizine was the most common individually prescribed medicine and fluconazole was the most commonly prescribed antifungal. Medicines prescribed by their generic name were $15.07 \%$ and those prescribed from national essential medicines list were $23.42 \%$. Conclusion: This study reveals polypharmacy, inclination of prescribers for branded medicines and prescribing out of national formulary as problems. Educational and managerial interventions are required to rationalize the prescribing practice.

Key words: Dermatological outpatients; polypharmacy; prescribing indicators.
\end{abstract}

Citation: Pradhan M. Evaluation of prescribing indicators and pattern among dermatological outpatients in a teaching hospital of central Nepal. JCMS Nepal. 2016;12(2):44-9.

\section{INTRODUCTION}

Irrational prescribing and inappropriate use of medicines have been reported as a common practice all over the world. ${ }^{1}$ Consequences of such bad practices are many in terms of wastage of available therapeutic resources, higher cost of treatment and adverse clinical conditions like ineffective and unsafe treatment, exacerbation or prolongation of existing illness, iatrogenic illness, increasing resistance to antimicrobials and ultimately an undue distress and harm to the patient. ${ }^{2}$ An effort was started in 1985 in the form of a global conference of experts at Nairobi to reduce such hazards and to promote rational prescribing and rational use of medicines so as to reduce the magnitude of these hazards. Rational use of medicines requires that patients receive medications appropriate to their clinical needs, in doses that meet their own individual requirements, at right time intervals, for an adequate period of time and at the lowest cost to them and their community. ${ }^{3}$ Rational prescribing is the most desired component of those steps that are needed to ensure the rational use of medicines and a cost-effective medical care.

It is extremely important to describe and quantify the problems in prescribing before an attempt is made to rationalize it. Prescriptions are a good source of information for determining prescribing indicators. ${ }^{4}$ Prescribing indicators are one of the core drug use indicators developed by the World Health Organization (WHO) in a combined effort with International Network for Rational Use of Drugs (INRUD). ${ }^{5}$ These indicators are widely accepted as a global standard for identification of some common problems associated with prescribing such as polypharmacy, inclination of prescribers for branded products, deviation from essential medicines list and overuse of costlier forms of treatments i.e. antibiotics and injections. ${ }^{6}$ These indicators also enable us to prioritize and focus subsequent efforts 
to correct these problems. These indicators can also be used to make comparisons between regions or countries and to measure the impact of interventions. ${ }^{7}$ Polypharmacy, inclination towards branded products and overuse of antibiotics were detected as problems in prescribing in previous studies conducted among orthopedic and medical outpatients of teaching hospital of College of Medical Sciences (CMSTH) Bharatpur. ${ }^{8,9}$ Polypharmacy and inclination of prescribers for branded products were also reported as problems in prescribing in a study conducted among dermatology outpatients in western Nepal. ${ }^{10}$ However, the investigators could not trace the data on prescribing indicators and pattern for the dermatological outpatients of the CMSTH Bharatpur to the best of their efforts. Therefore this study was planned and conducted in the same setting and institution with an objective to evaluate the prescribing indicators and to detect any existing problem in prescribing practice. The aim of this study also included to know the pattern of medicines prescribing in this specialty.

\section{MATERIALS AND METHODS}

This was a pharmacy based cross-sectional descriptive study conducted at the CMSTH Bharatpur. This is a tertiary care hospital located in the central Chitwan district of Nepal. Patients attending dermatological outpatient departments were approached at the pharmacy of the hospital on a predetermined day and time once in a week for their prescriptions over second four months (May to August) period of the year 2014. All the important informations contained on the original prescriptions were recorded on the duplex prescription sheets made by the investigators. The duplex prescription sheet was made in such a way to include almost all the columns that are needed to ensure the rational prescribing. Only freshly registered patients with their prescriptions were considered to record the data randomly and prospectively irrespective of age and sex. Revisit prescriptions and prescriptions having only suggested investigations were excluded from this study. The data obtained by this method from 325 original prescriptions were then critically analyzed under the guidelines of WHO as mentioned in "How to investigate drug use in health facilities: Selected drug use indicators" to find out the different parameters of prescribing indicators. ${ }^{5}$ Prescriptions were further analyzed to get the distribution of therapeutic classes of prescribed medicines and to get the prescribing frequency of individual medicines so as to know the pattern of medicines prescribing. Anti-protozoals such as Metronidazole and Tinidazole, anti-leprotics and anti-tuberculosis medicines were not considered as antibiotics and fixed dose combination (FDC) products were counted as single medicine as per the norms of WHO. All the prescribed medicines were compared with those enlisted in the concurrent national list of essential medicines to measure the deviation of the prescribers from the national formulary. ${ }^{11}$ The number and the percentage were used to express the observed data.

\section{RESULTS}

A total of 325 prescriptions belonging to same number of patients were analyzed. The total number of medicines prescribed on these prescriptions was 743. The average number of medicines per encounter was 2.28 . Only $112(15.07 \%)$ medicines out of 743 were prescribed by their generic names and only 174 (23.42\%) medicines were from the national formulary. Prescribing indicators are detailed in Table-1.

Medicines were prescribed in the range of 1-6. Majority (297, 91.38\%) of prescriptions were having up to three medicines and about two-third $(215,66.15 \%)$ of all prescriptions were containing not more than two medicines prescribed. There were only few $(28,8.61 \%)$ prescriptions, where more than three medicines were prescribed. Numbers of prescriptions consisting different numbers of medicines are detailed in Table-2.

Antihistaminics, antifungals, corticosteroids and antibiotics were the most frequently prescribed therapeutic classes in their descending order. Other less common classes of prescribed medicines were Vitamin B-Complex, anti-scabies agents, anti-acne agents, anthelmintics, sunscreen agents, antivirals

Table 1: Prescribing indicators among dermatological outpatients

\begin{tabular}{llc} 
Indicators & No. & $\mathbf{\%}$ \\
$\begin{array}{l}\text { Total Number of Prescriptions } \\
\text { Analyzed }\end{array}$ & 325 & 100 \\
$\begin{array}{l}\text { Total Number of medicines Prescribed } \\
\text { Average Number of Medicines }\end{array}$ & 743 & 100 \\
$\begin{array}{l}\text { Prescribed per Encounter } \\
\text { Medicines Prescribed by Generic }\end{array}$ & 2.28 & - \\
$\begin{array}{l}\text { Name } \\
\text { Encounters with Antibiotics }\end{array}$ & 93 & 112.07 \\
$\begin{array}{l}\text { Encounters with Injections } \\
\text { Medicines Prescribed from Essential } \\
\text { Medicines List of Nepal }\end{array}$ & 02 & 0.61 \\
\hline
\end{tabular}


Table 2: Number of prescriptions containing number of prescribed medicines

\begin{tabular}{|llll|}
$\begin{array}{l}\text { No. of } \\
\text { Medicines }\end{array}$ & $\begin{array}{l}\text { No. of } \\
\text { Such } \\
\text { Prescriptio } \\
\text { ns }\end{array}$ & $\begin{array}{l}\text { \% of Such } \\
\text { Prescriptio } \\
\text { ns }\end{array}$ & $\begin{array}{l}\text { No. of } \\
\text { Medicines } \\
\text { Prescribed }\end{array}$ \\
\hline 1 & 053 & 16.31 & 053 \\
\hline 2 & 162 & 49.84 & 324 \\
\hline 3 & 082 & 25.23 & 246 \\
\hline 4 & 023 & 7.08 & 092 \\
\hline 5 & 002 & 0.62 & 010 \\
\hline 6 & 003 & 0.92 & 018 \\
\hline Total & 325 & 100 & 743 \\
\hline
\end{tabular}

Table 3: Therapeutic Classes of prescribed medicines

\begin{tabular}{lll}
\hline Therapeutic Class & $\begin{array}{l}\text { Frequency } \\
\text { of } \\
\text { Prescription }\end{array}$ & $\begin{array}{l}\text { \%of } \\
\text { Prescribing } \\
\text { Frequency }\end{array}$ \\
\hline Antihistamines & 216 & 29.07 \\
\hline Antifungals & 144 & 19.38 \\
\hline Corticosteroids & 141 & 18.98 \\
\hline Antibiotics & 122 & 16.42 \\
\hline Vit. B Complex & 024 & 3.23 \\
\hline Anti-Scabies topical & 019 & 2.56 \\
\hline Anti-Acne topical & 013 & 1.75 \\
\hline $\begin{array}{l}\text { Anthelmintics } \\
\text { Sun-Screen Agents }\end{array}$ & 013 & 1.75 \\
$\begin{array}{l}\text { Miscellaneous (Drugs } \\
\text { for Alopecia \& Peptic } \\
\text { Ulcer, Anaesthetic gels, } \\
\text { Antiseptics, Antivirals }\end{array}$ & 040 & 1.48 \\
$\begin{array}{l}\text { Antileprotics, Anti- } \\
\text { inflammatory etc.) }\end{array}$ & & 5.38 \\
\begin{tabular}{l} 
Total \\
\hline
\end{tabular} & 743 & \\
\hline
\end{tabular}

etc. The details of therapeutic classes of prescribed medicines are mentioned in Table-3.

Further analysis of prescriptions revealed that 112 $(34.46 \%)$ prescriptions were having one systemic as well as one topical medicine belonging to same therapeutic class. There were two such different formulations of antibiotics in $48(14.77 \%)$ prescriptions and that of antifungals in $47(14.46 \%)$ prescriptions. Encounters with two such formulations of corticosteroids were $10(3.08 \%)$ and those with antihistaminics were 7 (2.15\%). Cetrizine remarkably ranked the first among individually prescribed medicines list with prescribing frequency of 272 out of a total of 743 medicines. Fluconazole, Clotrimazole and

Ketoconazole were three different individual antifungals that occupied the place among ten most frequently prescribed individual medicines. Table-4 details the top ten most frequently prescribed individual medicines.

\section{DISCUSSION}

The prescriptions reflect the overall attitude of the prescribing physicians along with their knowledge for the disease process and the pharmacotherapeutic approach adopted for the disease or condition. Inadequacy for these specific areas of knowledge among prescribers can contribute to polypharmacy. Polypharmacy is regarded as a form of overprescribing and a bad practice, as it complicates the therapeutic process by contributing to increased risk of adverse drug effects, drug-drug interactions and dispensing errors. ${ }^{12}$ Polypharmacy also contributes to non-compliance due to increased cost of treatment as well as due to increased complexity of therapy. ${ }^{13,14}$ The average number of medicines per encounter is the parameter among prescribing indicators that helps investigators to determine the existing attitude of prescribers regarding polypharmacy. This particular parameter was found to be 2.28 in our study. It was found to be 2.42 in the similar study of western Nepal. ${ }^{10}$ It was reported to be 3.36 in one similar north Indian study. ${ }^{15}$ This index was reported to be 2.6 and 2.7 in another two similar Indian studies conducted in two different locations. ${ }^{16,17}$ It was reported to be 3.06 in a similar study conducted in north Palestine. ${ }^{18}$ Thus, our observed value is less i.e. better in comparison to those reported in other similar national and international studies. Our observed value is better also in comparison to previous studies conducted in different outpatient departments of our hospital, where these figures were 2.8 in both instances. ${ }^{8,9}$ Therefore, the average number of medicines per

Table 4: Prescribing frequency of ten most commonly prescribed individual medicines

\begin{tabular}{ll} 
Name of Drug & $\begin{array}{l}\text { Prescribing } \\
\text { Frequency }\end{array}$ \\
\hline Cetrizine & 272 \\
\hline Ampicillin + Cloxacillin & 40 \\
Framycetin & 38 \\
Fluconazole & 34 \\
Clotrimazole & 33 \\
Ketoconazole & 32 \\
Betamethasone + Salicylic acid & 30 \\
Miconazole & 22 \\
Prednisolone & 20 \\
Cyproheptadine & 17
\end{tabular}


encounter found in our study points towards this fact that the prescribers of the concerned department are awared at least to some extent regarding the bad consequences of polypharmacy. This is also supported by the fact that majority $(>90 \%)$ of prescriptions contained not more than three drugs and about $67 \%$ of prescriptions were having not more than two drugs. However, the attitude of prescribers towards polypharmacy can not be neglected taking care the maximum limit of two medicines per encounter as set forth by WHO. ${ }^{6}$ Most frequently prescribed therapeutic classes in our study were antihistamines, antifungals, corticosteroids and antibiotics. This is almost in accordance with the reports of studies in western Nepal ${ }^{10}$ and India. ${ }^{15,17}$ Antifungals, antibiotics and corticosteroids were main therapeutic categories also in the study of north Palestine. ${ }^{18}$ The prescribing of antihistamines on such a large scale seems to be justified taking care its antiallergic as well as antipruiritic property. This is supported by the fact that allergy is one of the major causes of morbidity among patients attending dermatology department and skin allergies were found to be more common in rainy season in a report from central Nepal. ${ }^{19}$ Skin allergies are more likely also during our study as its major portion was conducted during rainy season. Apart from that, pruiritus is a symptom that occurs in a multitude of dermatological disorders including dry skin or xerosis, atopic eczema, urticaria and infections. ${ }^{20}$ Infective diseases account for much of the morbidity in developing countries like Nepal and India due to the fact that a vast majority of the population exists here under conditions of extreme poverty, inadequate medical care, poor sanitation and nutrition. ${ }^{21}$ In a recent point prevalence study, skin problems were reported to be the most common reason for people accessing health services in Nepal and dermatophyte infections were the most common skin diseases among them. ${ }^{22}$ Our study was conducted during the summer and monsoon seasons that favor the flare up of fungal and bacterial infections. This might have also contributed significantly to more prescribing of antifungals and antibiotics in our study. Corticosteroids are also widely used in dermatological practice owing to its potent antiinflammatory, immunosuppressive and anti-allergic activities. Thus the prescribing of these classes of medicines on a wide scale seems to be in accordance with the morbidity pattern of these developing countries and also corresponding to the probable seasonal prevalence of diseases during our study period. However, prescribing of two medicines (one systemic as well as one topical) from same therapeutic class (either antifungal or antibiotic or steroid or antihistamine) to an individual patient were also observed in about onethird prescriptions $(34.46 \%)$ in our study. The rationality for such prescribing needs to be judged in terms of the associated risk, benefit and cost of such therapy. There is also a need to investigate the exact existing morbidity pattern among dermatological outpatients of our hospital to justify the prescribing pattern of these medicines.

Cetrizine was the most frequently prescribed individual antihistaminic in our study. This was also the major individual therapeutic agent in this category in the north Indian study. ${ }^{15}$ Thus cetrizine seems to be a preferred antihistaminic as antipruiritic agent in dermatologic practice. This might be due to its suitability for once daily dosing, cost-effectiveness and safety perspective. Fluconazole was the most preferred antifungal agent in our as well as north Indian study. ${ }^{15}$ The likely reason for this preference is that the weekly dose of fluconazole provides convenient and costeffective treatment along with less risk of side effects.

In our study, $15.07 \%$ drugs were prescribed by their generic name. This is a better figure in comparison to that reported in the similar study conducted in western $\mathrm{Nepal}^{10}$ and in north India (Delhi) ${ }^{16}$, where this parameter were $13 \%$ and $6.98 \%$ respectively. This is also better in comparison to those observed in the study conducted among orthopedic outpatients of our hospital, where only $7.2 \%$ medicines were prescribed by generic name. 8 However, our finding in this concern is not better than those reported in two different studies of India conducted in two different locations, where this index were found to be $16.6 \%$ (Mumbai) ${ }^{17}$ and $24.22 \%$ (Ludhiana). ${ }^{15}$ Our finding is also not better in comparison to those observed in the study of medical outpatients of our hospital, as $20.31 \%$ medicines were reported to be prescribed by generic name. ${ }^{9}$ Therefore; our finding in this concern can be interpreted as the inclination of prescribers for prescribing the branded medicines. Unawareness of the prescribers regarding the benefits of prescribing by generic name or the unethical promotional incentives given to the prescribers by the various pharmaceutical companies to sell their products or 
both might be the possible reason for such deviation. Prescribing by generic name confers the least risk of dispensing errors and an ease to pharmacist for dispensing the prescribed medicine. This also confers to patients an ease in getting the medicines at the low cost in comparison to the branded products in case of price competition. The prescribers of the concerned department need their special attention to rectify this problem and to rationalize their practice.

The upper limit for the encounters with antibiotics and injections are $30 \%$ and $10 \%$ respectively as set forth by WHO.6 These parameters were found to be $28.61 \%$ and $0.61 \%$ respectively in our study. These are under the recommended limits and to be regarded as welcome sign. Prescribers of the concerned departments deserve appreciation for their awareness against these two costlier forms of treatment.

Medicines prescribed from national formulary were found to be $23.42 \%$ in our study. This is almost comparable to the reported $23 \%$ medicines from state formulary in Delhi based Indian study. ${ }^{16}$ However, our figure in this concern is very low and not satisfactory in comparison to those reported (46.2\% and $49.63 \%)$ in previous studies conducted in orthopedic and medical outpatients of our hospital respectively. ${ }^{8,9}$ The WHO emphasizes the prescribing of medicines as much as possible from the essential medicines list or hospital formulary, as medicines are selected for this list with due regard to disease prevalence and to the evidences of efficacy, safety and the cost of medicines. Unavailability of hospital formulary or national essential medicines list in the hospital is one important reason for such deviation. Another reason may be the unawareness of the prescribers regarding the significance of prescribing from such list.

\section{CONCLUSION}

Polypharmacy, inclination for branded products and prescribing out of national essential medicines list are some of the common problems revealed consequent to this study. Prescribers of the concerned department need their proper attention to rectify these problems and to rationalize their practice. Educational interventions aimed at rational prescribing and a multidirectional effort in the direction of institution of updated hospital formulary and standard treatment guidelines can help significantly to minimize these problems and to maximize cost-effective medical care. Managerial intervention like restricting maximum number of medicines per prescription may also help to minimize the related problem. Antihistamines, antifungals, antibiotics and steroids are the commonly prescribed therapeutic classes in dermatologic practice. Cetrizine and fluconazole are frequently prescribed antihistamine and antifungal respectively.

\section{REFERENCES}

1. Hogerzeil HV. Promoting rational prescribing: an international perspective. Br J Clin Pharmacol 1995; 39: 16. DOI: $10.1111 / j .1365-2125.1995 . t b 04402 . x$. PMID:7756093.

2. de Vries TPGM, Henning RH, Hogerzeil HV, Fresle DA Guide to good prescribing: a practical manual. Geneva: World Health Organization; 1994. WHO/DAP/94.11

3. WHO. The rational use of drugs. report of a conference of experts, Nairobi, 25- 29 November 1985. Geneva: World Health Organization, 1987.

4. WHO. Introduction to drug utilization research. Oslo: World Health Organization; 2003.

5. WHO. How to investigate drug use in health facilities: selected drug use indicators. Geneva: World Health Organization; 1993. WHO/DAP/93.1

6. WHO. Teacher's guide to good prescribing. Geneva: World Health Organization; 2001. WHO/EDM/ PAR/2001.2.

7. RO Laing, HV Hogerzeil, D Ross-Degnan. Ten recommendations to improve use of medicines in developing countries. Health Policy \& Planning 2001: 16 (1); 13-20. DOI: 10.1093/heapol/16.1.13. PMID:11238425.

8. Kumar J, Shaik MM, Kathi MC, Deka A, Gambhir SS Prescribing pattern and use of non-steroidal antiinflammatory drugs among orthopedic outpatients in a teaching hospital of central Nepal. JCMS Nepal 2008; 5(1) 80-6.

9. Kumar J, Shaik MM, Kathi MC, Deka A, Gambhir SS Prescribing indicators and pattern of use of antibiotics among medical outpatients in a teaching hospital of central Nepal. JCMS-Nepal 2010; 6(2): 7-13. DOI: 10.3126/ jcmsn.v6i2.3610.

10. C Sarkar, B Das, H Sripathi. Drug prescribing pattern in dermatology in a teaching hospital in western Nepal. J Nep Med Assoc 2001: 41: 241-6.

11. Department of Drug Administration. His Majesty's Government. National list of essential drugs Nepal (Third revision) 2002.

12. Holloway KA, Gautam BR. Consequences of overprescribing on the dispensing process in rural Nepal. Trop Med Int Health 2001: 6(2) : 151-4. DOI: 10.1046/j.13653156.2001.00695.x. PMID:11251911.

13. Bennet PN, Brown MJ. Topics in drug therapy. In: P.N. Bennet, M.J. Brown. Clinical pharmacology. 10th edi. Edinburgh: Churchill livingstone; 2008: 5-31. DOI: 10.1016/B978-0-443-10244-8.10002-3.

14. Buxton ILO. Principles of prescription order writing and patient compliance. In: L.L. Brunton, J.S. Lazo, K.L. 
Parker, editors. Goodman and Gilman's the pharmacological basis of therapeutics. 11th edi. New York: McGraw Hill; 2006. 1777-86.

15. Minocha KB, Bajaj S, Gupta K. A clinicopharmacological study of out patient prescribing pattern of dermatological drugs in Indian tertiary Hospital. Indian J Pharmacol 2002;32:384-5.

16. Maini R, Verma KK, Biswas NR, Agrawal SS. Medicine usage study in dermatology in a tertiary hospital in Delhi. Indian J Physiol Pharmacol. 2002;46:107-10.

17. Narwane SP, Patel TC, Shetty YC, Chikhalkar SB. Drug utilization and cost analysis for common skin diseases in dermatology OPD of an Indian tertiary care hospital-A prescription survey. Br J Pharm Res. 2011;1(1):9-18. DOI: 10.9734/BJPR/2011/223.

18. W.M. Sweileh. Audit of prescribing practices of topical corticosteroids in outpatient dermatology clinics in north Palestine. Eastern Mediterranean Health Journal 2006: 12 (1/2): 161-9. PMID:17037234.

19. Pokhrel DB, Joshi DD, Bohara MS. Pattern of cutaneous allergy in the dermatology department of TUTH (20052007). J Nep Health Res Council 2007: 5(2): 33-8.

20. Fox LP, Merk HF, Bickers DR. Dermatological pharmacology. In: L.L. Brunton, J.S. Lazo, K.L. Parker, editors. Goodman and Gilman's the pharmacological basis of therapeutics. 11th edi. New York: McGraw Hill; 2006. 1679-706.

21. Walsh JA, Warren KS. Selective primary health care: An interim strategy for disease control in developing countries. N Eng J Med 1979; 301: 967 - 74. DOI: 10.1056/ NEJM197911013011804. PMID:114830.

22. Walkar SL, Shah M, Hubbard VG, Walkar SL, Shah M, Hubbard VG, et al. Skin disease is common in rural Nepal: results of a point prevalence study. Br J Dermatol 2008; 158(2): $334-8$. 